\title{
Dietary sources of vitamin C, vitamin E and specific carotenoids in Spain
}

\author{
Reina García-Closas ${ }^{1 *}$, Antonio Berenguer ${ }^{1}$, María José Tormo ${ }^{2}$, María José Sánchez ${ }^{3}$, \\ José R. Quirós ${ }^{4}$, Carmen Navarro ${ }^{2}$, Rosario Arnaud ${ }^{3}$, Miren Dorronsoro ${ }^{5}$, \\ María Dolores Chirlaque ${ }^{2}$, Aurelio Barricarte ${ }^{6}$, Eva Ardanaz ${ }^{6}$, Pilar Amiano ${ }^{5}$, Carmen Martinez $^{3}$, \\ Antonio Agudo ${ }^{1}$ and Carlos A. González ${ }^{1}$ \\ ${ }^{1}$ Institut Català d'Oncologia, 08907 Barcelona, Spain \\ ${ }^{2}$ Consejería de Sanidad y Consumo, 30008 Murcia, Spain \\ ${ }^{3}$ Escuela Andaluza de Salud Pública, 18080 Granada, Spain \\ ${ }^{4}$ Consejería de Sanidad y Servicios Sociales de Asturias, 33001 Oviedo, Spain \\ ${ }^{5}$ Dirección de Salud de Guipúzkoa, 20013 San Sebastián, Spain \\ ${ }^{6}$ Departamento de Salud de Navarra, 31003 Pamplona, Spain
}

(Received 14 August 2003 - Revised 27 January 2004 - Accepted 16 February 2004)

\begin{abstract}
A cross-sectional study was conducted within the Spanish cohort of the European Prospective Investigation in Cancer and Nutrition to assess the principal food sources of vitamin $\mathrm{C}$, vitamin $\mathrm{E}, \alpha$-carotene, $\beta$-carotene, lycopene, lutein, $\beta$-cryptoxanthin and zeaxanthin in an adult Spanish population. The study included 41446 healthy volunteers (25812 women and 15634 men), aged 29-69 years, from three Spanish regions in the north (Asturias, Navarra and Guipúzcoa) and two in the south (Murcia and Granada). Usual food intake was estimated by personal interview through a computerized version of a dietary history questionnaire. Foods that provided at least two-thirds of the studied nutrients were: fruits (mainly oranges) $(51 \%)$ and fruiting vegetables (mainly tomato and sweet pepper) $(20 \%)$ for vitamin $\mathrm{C}$; vegetable oils (sunflower and olive) $(40 \%)$, non-citrus fruits $(10 \%)$, and nuts and seeds $(8 \%)$ for vitamin $\mathrm{E}$; root vegetables (carrots) $(82 \%)$ for $\alpha$-carotene; green leafy $(28 \%)$, root $(24 \%)$ and fruiting vegetables $(22 \%)$ for $\beta$-carotene; fruiting vegetables (fresh tomato) (72\%) for lycopene; green leafy vegetables (64\%) for lutein; citrus fruits (68\%) for $\beta$-cryptoxanthin; citrus fruits $(43 \%)$ and green leafy vegetables $(20 \%)$ for zeaxanthin. In conclusion, the main food sources of nutrients with redox properties have been identified in a Mediterranean country. This could provide an insight into the interpretation of epidemiological studies investigating the role of diet in health and disease.
\end{abstract}

Antioxidants: Mediterranean diet: Spain: Food sources

Foods of plant origin are the main dietary sources of vitamin $\mathrm{C}$, vitamin $\mathrm{E}$ and carotenoids, which, among other plant constituents, could act as efficient scavengers of radicals and oxidants (Frei, 1994; McDermott, 2000). Scientific evidence shows that plant-based diets, such as the traditional Mediterranean diet, could protect against CVD (de Lorgeril \& Salen, 2001) and cancer (World Cancer Research Fund, 1997). Those nutrients with redox modulator properties could also have beneficial effects on the risk of other chronic diseases, such as diabetes, neurodegenerative diseases, ocular disorders, as well as in asthma and viral infections (Frei, 1994; McDermott, 2000).

Vitamin C, vitamin E, $\beta$-carotene, and more recently lycopene and other specific carotenoids, have been the subject of many observational studies assessing their association with chronic diseases (Frei, 1994; McDermott, 2000;
Fairfield \& Fletcher, 2002). Overall, these observational studies have supported an inverse association of those nutrients with CVD and cancer (Fairfield \& Fletcher, 2002). However, the hypothesis that those individual nutrients act mainly as markers of intake of foods with many compounds that act synergistically to protect from chronic diseases could not be ruled out (Byers, 2000; McDermott, 2000; de Lorgeril \& Salen, 2001). Clinical trials with supplements of single nutrients, especially $\beta$-carotene, have produced discouraging results (Halliwell, 2000; Fairfield \& Fletcher, 2002; Kritharides \& Stocker, 2002). Overall, these trials suggest that a protective effect of foods is not equivalent to a protective effect of single nutrients in the diet.

The assessment of food sources of nutrients with redox properties could be useful for the interpretation of epidemiological studies. However, few studies have attempted 
to identify intakes of such foods in populations with different chronic disease rates (Krogh et al. 1993; Heseker \& Schneider, 1994; Jarvinen, 1995; Granado et al. 1996; Vandenlangenberg et al. 1996; Subar et al. 1998; Gascón-Vila et al. 1999; O’Neill et al. 2001; JohnsonDown et al. 2002).

In Spain, a country in the Mediterranean area, fruit and vegetable consumption is substantially higher and qualitatively different from consumption in other western countries (EPIC Group of Spain, 1999; Trichopoulou \& Vasilopoulou, 2000; Moreno et al. 2002; Agudo et al. 2002). Meanwhile, the Spanish IHD mortality rate is the lowest among European countries (Tundstall-Pedoe et al. 1999) and its cancer mortality rate ranks the third lowest to Greece and Portugal (World Health Organization, 2003). The two previous studies assessing Spanish food sources of nutrients with redox properties did not assess specific carotenoids (Gascón-Vila et al. 1999) or were based on small samples (O'Neill et al. 2001). The present study examines the main food sources of vitamin $C$, vitamin $E$ and major specific carotenoids ( $\alpha$-carotene, $\beta$-carotene, lycopene, lutein, $\beta$-cryptoxanthin and zeaxanthin) in a large cohort of the Spanish adult population.

\section{Materials and methods}

\section{Human subjects}

Cross-sectional dietary data from 25812 women and 15634 men, aged 29-69 years, participants in the European Prospective Investigation in Cancer and Nutrition (EPIC), were obtained between October 1992 and July 1996. Participants were healthy volunteers recruited in five Spanish regions: three from the north (Asturias, Navarra and Guipúzcoa) and two from the south (Murcia and Granada). Most of the selected subjects were active blood donors. The mean ages of participants were $50 \cdot 8$ and 48.4 years for men and women respectively. Final participation rate was $55-60 \%$.

\section{Dietary information}

Usual food intake during the preceding year, taking into account seasonal variations, was estimated by personal interview through a computerized version of a dietary history questionnaire. It was developed and validated specifically for the EPIC study in Spain (EPIC Group of Spain, $1997 a, b)$. The questionnaire was structured according to occasions of food intake. Trained interviewers gathered data on preparation method, average frequency of consumption per week, and usual portion size for each food consumed at least twice per month (or once per month for seasonal foods). The estimated intake data represented all the seasons equally. Portion sizes were reported in natural units, household measures or with the aid of a manual of thirty-five sets of photographs prepared specifically for the study. The questionnaire included a list of $>600$ foods and beverages, and about 150 regional recipes. Data on vitamin C, vitamin E, pro-vitamin A carotenoids, $\alpha$-carotene, $\beta$-carotene, lycopene, lutein, $\beta$-cryptoxanthin and zeaxanthin in foods were obtained from a computerized database of $>700$ items compiled for the EPIC study in Spain (Slimani et al. 1996). Values for individual carotenoids were mainly obtained from analyses performed on local foods (Olmedilla et al. 1996) and a recently available European database was used to complete missing values (O’Neill et al. 2001). Pro-vitamin A carotenoid intake was expressed as $\mu \mathrm{g} \beta$-carotene equivalents/d $(1 \beta$-carotene equivalent $=1 \beta$-carotene $+0 \cdot 5 \alpha$-carotene + $0 \cdot 5 \beta$-cryptoxanthin).

\section{Statistical analyses}

A descriptive statistical analysis was performed and intakes were expressed as mean values and standard deviations, and as 25 th, 50th and 75 th percentiles. Densities of intake were expressed as $\mathrm{mg} / 4.2 \mathrm{MJ}(1000 \mathrm{kcal})$ per $\mathrm{d}$ for vitamin $\mathrm{C}$ and vitamin $\mathrm{E}$ and as $\mu \mathrm{g} / 4 \cdot 2 \mathrm{MJ}(1000 \mathrm{kcal})$ per $\mathrm{d}$ for provitamin $\mathrm{A}$ carotenoids, $\alpha$-carotene, $\beta$-carotene, lycopene, lutein, $\beta$-cryptoxanthin and zeaxanthin. When comparing intakes between centres, intakes were gender and age-standardized using linear regression analysis.

To identify food sources, the total amount of a given nutrient provided by a single food was calculated by multiplying the food consumed $(\mathrm{g} / \mathrm{d})$ by each subject by the amount of nutrient per $g$ food, and then adding up the resulting quantities from all subjects. Individual foods were also aggregated in food groups according to the way they were usually reported and their nutrient content. The list of food groups is given in the appendix. Intake of a given nutrient from each group was estimated by adding up the intake from each individual food included in the group. Data were analysed with the R Project for Statistical Computing (www.r-project.org).

\section{Results}

Means values and percentiles of intake for vitamin $C$, vitamin E, pro-vitamin A carotenoids, $\alpha$-carotene, $\beta$-carotene, lycopene, lutein, $\beta$-cryptoxanthin and zeaxanthin in the studied population are shown in Table 1. The median intakes of vitamin $\mathrm{C}$, vitamin $\mathrm{E}$ and total carotenoids (the sum of the six carotenoids) were $138.1,8.5$ and $4.8 \mathrm{mg} / \mathrm{d}$ respectively. Nearly $50 \%$ of carotenoids were in the form of pro-vitamin A carotenoids.

Table 2 shows the main food sources of vitamin $\mathrm{C}$, vitamin E and pro-vitamin A carotenoids, as well as the median consumption of each food group. Fresh fruits accounted for $51 \%$ of vitamin $\mathrm{C}$ intake, followed by fruiting vegetables (especially tomato and sweet pepper) and juices. Although oranges were the main source of vitamin $\mathrm{C}$, the non-citrus fruit subgroup accounted for $21 \%$ of intake. The greatest proportion of vitamin $\mathrm{E}$ intake came from vegetable oils (26\% from sunflower oil and $14 \%$ from olive oil), whereas other added fats (margarine, mayonnaise, butter and lard) accounted for $<5 \%$. Nuts and seeds contributed modestly to vitamin $\mathrm{E}$ intake. It is noteworthy that $>25 \%$ of vitamin $\mathrm{E}$ intake was derived from fresh fruits (especially apples and pears) and 
Table 1. Distribution of vitamin $C$, vitamin $E$ and carotenoid intake in the Spanish EPIC cohort*

(Mean values, standard deviations and median percentiles)

\begin{tabular}{|c|c|c|c|c|c|}
\hline \multirow[b]{2}{*}{ Intake (per d) } & \multirow[b]{2}{*}{ Mean } & \multirow[b]{2}{*}{ SD } & \multicolumn{3}{|c|}{ Median percentile } \\
\hline & & & 25th & 50th & 75th \\
\hline \multicolumn{6}{|l|}{ Vitamin C } \\
\hline $\mathrm{mg}$ & $152 \cdot 0$ & $83 \cdot 7$ & 94.5 & $138 \cdot 1$ & $192 \cdot 3$ \\
\hline $\mathrm{mg} / 4 \cdot 2 \mathrm{MJ} \dagger$ & 71.9 & $43 \cdot 7$ & 41.7 & 63.2 & $91 \cdot 8$ \\
\hline \multicolumn{6}{|l|}{ Vitamin $\mathrm{E}$} \\
\hline & $10 \cdot 4$ & $6 \cdot 5$ & $6 \cdot 2$ & 8.5 & $12 \cdot 4$ \\
\hline $\mathrm{mg} / 4 \cdot 2 \mathrm{MJ} \dagger$ & 4.6 & 2.5 & 3.0 & 3.9 & $5 \cdot 6$ \\
\hline \multicolumn{6}{|c|}{ Pro-vitamin A carotenoids $\ddagger$} \\
\hline$\mu \mathrm{g}$ & $2349 \cdot 5$ & $1496 \cdot 2$ & $1376 \cdot 1$ & $2000 \cdot 1$ & $2903 \cdot 0$ \\
\hline $\begin{array}{c}\mu \mathrm{g} / 4.2 \mathrm{MJ} \dagger \\
\alpha \text {-Carotene }\end{array}$ & $1105 \cdot 8$ & $802 \cdot 0$ & $618 \cdot 9$ & $904 \cdot 1$ & $1335 \cdot 1$ \\
\hline$\mu \mathrm{g}$ & 263.4 & $366 \cdot 5$ & $76 \cdot 2$ & $146 \cdot 1$ & $288 \cdot 8$ \\
\hline $\begin{array}{c}\mu \mathrm{g} / 4.2 \mathrm{MJ} \dagger \\
\beta \text {-Carotene }\end{array}$ & $126 \cdot 2$ & $193 \cdot 8$ & 34.5 & $66 \cdot 2$ & $134 \cdot 3$ \\
\hline$\mu \mathrm{g}$ & $1993 \cdot 6$ & $1293 \cdot 0$ & $1147 \cdot 7$ & 1678.5 & 2476.9 \\
\hline$\mu \mathrm{g} / 4 \cdot 2 \mathrm{MJ} \dagger$ & 937.9 & 693.3 & $515 \cdot 0$ & $759 \cdot 0$ & 1134.4 \\
\hline \multicolumn{6}{|l|}{ Lycopene } \\
\hline$\mu \mathrm{g}$ & $2087 \cdot 2$ & $1439 \cdot 8$ & $1061 \cdot 6$ & 1797.5 & $2787 \cdot 1$ \\
\hline$\mu \mathrm{g} / 4 \cdot 2 \mathrm{MJ} \dagger$ & 973.0 & $719 \cdot 1$ & $477 \cdot 2$ & $808 \cdot 8$ & 1285.5 \\
\hline \multicolumn{6}{|l|}{ Lutein } \\
\hline$\mu \mathrm{g}$ & $770 \cdot 1$ & 797.9 & $340 \cdot 1$ & $546 \cdot 8$ & $900 \cdot 0$ \\
\hline $\begin{array}{c}\mu \mathrm{g} / 4 \cdot 2 \mathrm{MJ} \dagger \\
\beta-\text {-Cryptoxanthin }\end{array}$ & 368.8 & $436 \cdot 0$ & $152 \cdot 9$ & 249.3 & $416 \cdot 7$ \\
\hline$\mu \mathrm{g}$ & 635.3 & 578.0 & 222.9 & $495 \cdot 3$ & $875 \cdot 4$ \\
\hline$\mu \mathrm{g} / 4 \cdot 2 \mathrm{MJ} \dagger$ & $302 \cdot 6$ & 293.5 & $100 \cdot 5$ & 229.0 & $410 \cdot 9$ \\
\hline Zeaxanthin & & & & & \\
\hline$\mu \mathrm{g}$ & $132 \cdot 7$ & $97 \cdot 4$ & 65.4 & $109 \cdot 7$ & $171 \cdot 3$ \\
\hline$\mu \mathrm{g} / 4 \cdot 2 \mathrm{MJ} \dagger$ & 61.9 & $49 \cdot 8$ & 29.1 & $50 \cdot 0$ & $79 \cdot 7$ \\
\hline
\end{tabular}

* For details of subjects and procedures, see p. 1006.

$\dagger 1000 \mathrm{kcal}$

$\ddagger \mu \mathrm{g} \beta$-carotene equivalent.

vegetables (mainly tomato and lettuce). Pro-vitamin A carotenoids were consumed largely $(70 \%)$ from root, green leafy and fruiting vegetables: carrots, tomatoes, spinach, chard, leek and borage were major individual food contributors. Oranges were also a good source of pro-vitamin A $(10 \%)$.

Table 3 shows the primary contributors to intakes of $\alpha$-carotene, $\beta$-carotene, lycopene, lutein, $\beta$-cryptoxanthin and zeaxanthin. Root vegetables (carrots) served as the main source of $\alpha$-carotene intake $(82 \%)$. The richest sources of $\beta$-carotene were green leafy, root and fruiting vegetables, each contributing approximately $25 \%$ to total intake. As individual foods, carrots, tomatoes and spinach were the three main sources of $\beta$-carotene. Fruiting vegetables were the major contributors to lycopene intake: fresh tomatoes provided $72 \%$ and tomato sauce $24 \%$, whereas ketchup supplied $<1 \%$. Green leafy vegetables (mainly spinach, chard and lettuce) ranked first as a source of lutein $(64 \%)$; fruiting vegetables made a moderate contribution. Citrus fruits accounted for most of the $\beta$-cryptoxanthin intake, and major contributors to zeaxanthin intake were, in descending order, citrus fruits, green leafy and fruiting vegetables.

When comparing sources of the studied nutrients between southern and northern Spanish regions, it is striking that in southern regions citrus fruits accounted for a higher proportion of vitamin $\mathrm{C}$ intake, olive oil and nuts ranked higher for vitamin $\mathrm{E}$ intake, and fresh tomatoes provided relatively more lycopene (results not shown).

\section{Discussion}

The present study describes the main food sources of vitamin $\mathrm{C}$ and $\mathrm{E}$ and specific carotenoids in an adult Spanish population. Spain, which is a country of the Mediterranean region, has one of the lowest mortality rates from chronic diseases in developed countries and one of the best lifeexpectancy rates in the world (Parkin et al. 1997; Tundstall-Pedoe et al. 1999; United Nations International Children's Emergency Fund, 2003). No data on intakes of nutrients from supplements were included in the analyses, since only food sources were of interest. However, supplement use was only $3.8 \%$ in the Spanish EPIC cohort (Pera et al. 1999) and it contributed very little to overall intakes (results not shown).

The contribution to total nutrient intake of a particular food reflects not only its nutrient content, but also the amount of food consumed. In the Spanish EPIC cohort, oranges and apples accounted for $51 \%$ of fruit intake, and tomato and lettuce accounted for $47 \%$ of vegetable intake (EPIC Group of Spain, 1999). These four foods provided about $75 \%$ of lycopene, $50 \%$ of vitamin $C, \beta$-cryptoxanthin and zeaxanthin, $25 \%$ of $\beta$-carotene and lutein, and $4 \%$ of $\alpha$-carotene intake. Carrots represented only $3 \%$ of total vegetable consumption in the Spanish EPIC cohort, but they provided most of $\alpha$-carotene intake because their $\alpha$-carotene concentration is very high. Oranges and tomatoes contain high concentration of $\beta$-cryptoxanthin and lycopene respectively, and at the same time they were consumed frequently, mainly as fresh but also as processed foods, thus contributing up to $75 \%$ of their intake. The main sources of vitamin $\mathrm{E}$ were found in vegetable oils, which is the type of added fat most frequently consumed by the cohort. In spite of the relatively low content of vitamin $\mathrm{E}$ in fruits and vegetables, they accounted for $>25 \%$ of its intake because they had an important contribution to the whole diet. Although margarine, and nuts and seeds are very rich in vitamin $\mathrm{E}$, they were not a major source of intake ( 3 and $8 \%$ respectively) since they were consumed in low amounts.

The main food sources of vitamin C, vitamin E and carotenoids in Spain and the USA are compared in Table 4. Median vitamin $\mathrm{C}$ and $\mathrm{E}$ intakes were higher in the Spanish population than in the USA (138v. 85 and $8.5 v .6 .4 \mathrm{mg} / \mathrm{d}$ respectively). Fresh fruits provided $51 \%$ of vitamin $\mathrm{C}$ in Spain and only $9 \%$ in the USA, whereas fruit juices accounted for $7 \%$ of vitamin C intake in Spain and $34 \%$ in the USA. Added fats were major contributors to vitamin $E$ intake in both populations; however, vegetable oils were the main source in Spain (40\%), while they accounted for only $5 \%$ in the USA. Furthermore, olive oil, which is rich in antioxidant compounds other than vitamin $\mathrm{E}$ (Trichopoulou \& Vasilopoulou, 2000), accounted for $14 \%$ of vitamin E intake in the Spanish EPIC cohort and $<1 \%$ in the USA; margarine and salad dressings were the main vitamin E sources in the USA (29\%) and accounted for $<3 \%$ in the Spanish cohort. Fortified cereals were responsible for 4 and $10 \%$ of total vitamin $\mathrm{C}$ and vitamin $\mathrm{E}$ intake in the USA, but they were negligible sources of those vitamins in Spain. The principal contributors to pro-vitamin A carotenoid intake were vegetables, both in the USA 
Table 2. Main dietary sources of vitamin C, vitamin E and pro-vitamin A carotenoids in the Spanish EPIC cohort*

\begin{tabular}{|c|c|c|c|c|}
\hline Food group $†$ & Median intake (g/d) & Vitamin C (\%)‡ & Vitamin $\mathrm{E}(\%) \S$ & Pro-vitamin A carotenoids (\%)| \\
\hline Potatoes & $70 \cdot 4$ & $3 \cdot 9$ & $0 \cdot 8$ & 0.0 \\
\hline Green leafy vegetables & 54.5 & $6 \cdot 7$ & 3.6 & $23 \cdot 8$ \\
\hline Fruiting vegetables & 89.5 & $20 \cdot 3$ & $7 \cdot 4$ & $19 \cdot 3$ \\
\hline Root vegetables & 3.9 & 0.4 & 0.4 & $25 \cdot 3$ \\
\hline Cruciferous vegetables & $1 \cdot 2$ & $2 \cdot 9$ & 0.4 & 0.2 \\
\hline Grain and pod vegetables & 0.8 & 0.2 & $0 \cdot 1$ & 0.5 \\
\hline Onion and garlic & $18 \cdot 3$ & 1.0 & 0.9 & $0 \cdot 0$ \\
\hline Stalk vegetables & $1 \cdot 2$ & 0.9 & 0.8 & 0.0 \\
\hline Pulses (legumes) & $45 \cdot 1$ & $2 \cdot 1$ & $3 \cdot 1$ & $2 \cdot 8$ \\
\hline Citrus fruits & $37 \cdot 1$ & $29 \cdot 6$ & 1.9 & $10 \cdot 3$ \\
\hline Non-citrus fruits & $210 \cdot 2$ & 21.5 & $9 \cdot 7$ & $6 \cdot 1$ \\
\hline Juices & 0.6 & $6 \cdot 3$ & 0.0 & 0.2 \\
\hline Nuts and seeds & 0.0 & 0.0 & 7.9 & $0 \cdot 1$ \\
\hline Milk and dairy products & 272.4 & 2.4 & $3 \cdot 2$ & $2 \cdot 7$ \\
\hline Grains (cereals) & $213 \cdot 8$ & 0.0 & 1.6 & 0.0 \\
\hline Meats and poultry & $118 \cdot 7$ & 0.3 & 1.4 & $2 \cdot 8$ \\
\hline Fish and shellfish & 54.5 & 0.0 & 6.5 & 0.0 \\
\hline Eggs & 21.9 & 0.0 & $2 \cdot 7$ & 0.0 \\
\hline Added fats & $28 \cdot 0$ & 0.0 & 43.5 & 1.0 \\
\hline Condiments and sauces & $8 \cdot 3$ & 1.0 & $2 \cdot 0$ & 3.7 \\
\hline
\end{tabular}

${ }^{*}$ For details of subjects and procedures, see p. 1006.

tSee appendix for composition of food groups. Groups which contributed $<1 \%$ to the intake of vitamin $\mathrm{C}$, vitamin $\mathrm{E}$ and carotenoids were not listed in the table (grain and pod vegetables; stalk vegetables; sugars, sweets and desserts; non-alcoholic beverages; alcoholic beverages, mushrooms, soups and bouillon and others (processed foods))

‡Foods contributing $>1 \%$, in descending order (\%): orange (27.6), tomato (12.0), apple (7.2), sweet pepper (7.2), kiwi (6.6), orange juice (5.4), lettuce (3.9), potato (3.7), strawberries $(2 \cdot 1)$, milk (2.1), fava beans (1.9), tangerine (1.6), chard (1.3), peach (1.3), melon (1.2), cauliflower (1.1).

$\S$ Foods contributing $>1 \%$, in descending order (\%): sunflower oil (26.1), olive oil (13.7), tomato (6.0), apple (3.1), margarine (2.9), eggs (2.7), pear (2.6), almonds (2.6), lettuce (2.4), sunflower or pumpkin seeds (2.4), canned tuna $(2 \cdot 1)$, orange $(1 \cdot 7)$, cheese $(1 \cdot 5)$, chickpeas $(1 \cdot 5)$, milk $(1 \cdot 4)$, mayonnaise $(1 \cdot 3)$, wholegrain bread $(1 \cdot 3)$, hazelnuts $(1 \cdot 2)$, pine kernels $(1 \cdot 2)$, peach $(1 \cdot 2)$.

$\|$ Foods contributing $>1 \%$, in descending order (\%): carrot (25.3), tomato (14.6), orange (10.0), spinach (9.1), chard (6.4), borage and leek (5.0), tomato sauce (3.3), green beans (3.3), cured sausage (2.5), lettuce (2.3), melon (2.3), sweet pepper (1.3), mid-cured cheese (1.2), milk $(1 \cdot 1)$, peach (1.1), chickpeas (1.1). Pro-vitamin A carotenoid intake was expressed as $\beta$-carotene equivalent $(1 \beta$-carotene equivalent $=$ $1 \beta$-carotene $+0.5 \alpha$-carotene $+0.5 \beta$-cryptoxanthin)

Table 3. Main dietary sources of specific carotenoids in the Spanish EPIC cohort ${ }^{\star}$

\begin{tabular}{|c|c|c|c|c|c|c|}
\hline Food group $†$ & $\alpha$-Carotene $(\%) \ddagger$ & $\beta$-Carotene $(\%) \S$ & Lycopene (\%)\| & Lutein (\%)ף & $\beta$-Cryptoxanthin (\%) ${ }^{\star *}$ & Zeaxanthin (\%)†† \\
\hline Potatoes & 0.0 & 0.0 & 0.0 & 1.9 & 0.0 & $12 \cdot 7$ \\
\hline Green leafy vegetables & 0.0 & $27 \cdot 7$ & 0.0 & 64.5 & 0.0 & $20 \cdot 1$ \\
\hline Fruiting vegetables & $7 \cdot 8$ & $22 \cdot 0$ & $71 \cdot 6$ & $17 \cdot 6$ & $2 \cdot 4$ & $12 \cdot 6$ \\
\hline Root vegetables & $81 \cdot 6$ & 24.4 & 0.0 & $2 \cdot 0$ & 0.0 & 0.0 \\
\hline Cruciferous vegetables & 0.0 & 0.6 & 0.0 & 2.5 & 0.0 & 0.2 \\
\hline Grain and pod vegetables & 0.3 & 0.5 & 0.0 & $2 \cdot 8$ & 0.0 & 0.0 \\
\hline Stalk vegetables & 0.0 & 0.3 & 0.0 & $2 \cdot 7$ & 4.8 & $3 \cdot 6$ \\
\hline Pulses (legumes) & 0.4 & $3 \cdot 2$ & 0.0 & 0.0 & 0.0 & 0.0 \\
\hline Citrus fruits & 4.4 & $2 \cdot 3$ & 0.0 & 5.4 & $67 \cdot 6$ & $42 \cdot 8$ \\
\hline Non-citrus fruits & $4 \cdot 1$ & $6 \cdot 2$ & $2 \cdot 9$ & $3 \cdot 3$ & 4.9 & 7.9 \\
\hline Juices & $1 \cdot 0$ & $0 \cdot 1$ & 0.2 & 0.0 & $20 \cdot 2$ & 0.0 \\
\hline Milk and dairy products & 0.0 & $3 \cdot 2$ & 0.0 & 0.0 & 0.0 & 0.0 \\
\hline Meats and poultry & 0.0 & $2 \cdot 7$ & 0.0 & 0.0 & 0.0 & 0.0 \\
\hline Added fats & 0.0 & $1 \cdot 1$ & $0 \cdot 0$ & 0.0 & 0.0 & 0.0 \\
\hline Condiments and sauces & 0.4 & $4 \cdot 3$ & $25 \cdot 3$ & $0 \cdot 0$ & 0.0 & 0.0 \\
\hline
\end{tabular}

${ }^{*}$ For details of subjects and procedures, see p. 1006.

† See appendix for composition of food groups. Groups which contributed $<1 \%$ to the specific carotenoid intake were not listed in the table (grains; onion and garlic; nuts and seeds; eggs; fish and shellfish; sugars, sweets and desserts; non-alcoholic beverages; alcoholic beverages, mushrooms, soups and bouillon and others (processed foods)).

$\ddagger$ Foods contributing $>1 \%$, in descending order (\%): carrot (81.6), green beans (7.7), orange (4.2), banana (2.3).

$\S$ Foods contributing $>1 \%$, in descending order $(\%)$ : carrot $(24 \cdot 4)$, tomato $(17 \cdot 2)$, spinach $(10 \cdot 7)$, chard $(7 \cdot 5)$, borage $(5 \cdot 9)$, tomato sauce $(3.9)$, green beans $(3.0)$, lettuce (2.7), melon (2.7), cured sausage (2.4), orange (2.0), cheese (1.4), sweet pepper (1.3), milk (1.3), chickpeas (1.2).

$\|$ Foods contributing $>1 \%$, in descending order (\%): tomato (71.6), tomato sauce (24.1), watermelon (2.9).

9 Foods contributing $>1 \%$, in descending order (\%): spinach (28.2), chard (20.6), lettuce (15.9), green beans (11.7), orange (5.4), tomato (3.4), artichoke (2.1), carrot $(2 \cdot 0)$, potato $(1 \cdot 9)$, leek $(1 \cdot 1)$, broccoli $(1 \cdot 1)$, asparagus $(1 \cdot 1)$.

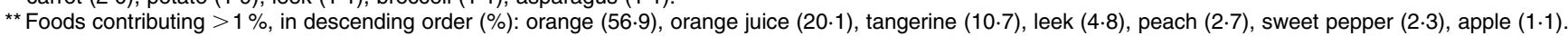
†† Foods contributing $>1 \%$, in descending order $(\%)$ : orange $(42 \cdot 8)$, spinach $(20 \cdot 1)$, sweet pepper $(12 \cdot 6)$, potato (12.5), peach (5.8), leek (3.8), tangerine (1.8). 
Table 4. Food sources of vitamin C, vitamin $E$ and pro-vitamin A carotenoids in Spain and the USA $^{*}$

\begin{tabular}{|c|c|c|c|c|}
\hline & \multicolumn{2}{|l|}{ Spaint } & \multicolumn{2}{|l|}{ USA } \\
\hline & Food group & $\%$ & Food group & $\%$ \\
\hline \multirow[t]{4}{*}{ Vitamin C } & Fruits & 51 & Juices and drinks & 34 \\
\hline & Vegetables & 32 & Vegetables & 23 \\
\hline & Juices and drinks & 7 & Fruits & 9 \\
\hline & Potatoes & 4 & Potatoes & 7 \\
\hline \multirow[t]{5}{*}{ Vitamin E } & Fats and oils & 44 & Fats and oils & 31 \\
\hline & Vegetables & 15 & Ready-to-eat cereals & 10 \\
\hline & Fruits & 12 & Meat, poultry and fish & 8 \\
\hline & Meat, poultry and fish & 8 & Desserts & 8 \\
\hline & Nuts and seeds & 8 & Eggs & 5 \\
\hline \multirow[t]{4}{*}{ Pro-vitamin A carotenoids } & Vegetables & 69 & Vegetables & 72 \\
\hline & Fruits & 16 & Sweet potatoes & 5 \\
\hline & Tomato sauce & 3 & Fruits & 3 \\
\hline & Pulses & 3 & Juices & 3 \\
\hline
\end{tabular}

${ }^{*}$ For details of subjects and procedures, see p. 1006

†From Spanish EPIC cohort, 1992-96.

†From Continuing Survey of Food Intakes of Individuals, 1989-91 (Subar et al. 1998).

and Spain. While carrots accounted for $53 \%$ of its intake in the USA and $25 \%$ in Spain, other vegetables accounted for $19 \%$ in the USA and $44 \%$ in Spain. Finally, fruits were an important source of vitamin $\mathrm{C}$, vitamin $\mathrm{E}$ and pro-vitamin A carotenoids in the Spanish cohort (51, 12 and 16\% respectively), while they were poor sources in the USA (9, 2 and $3 \%$ respectively; Vandenlangenberg et al. 1996). This different pattern of fruit and vegetable intake was reflected in a higher intake of $\alpha$-carotene and lower intake of $\beta$-carotene and $\beta$-cryptoxanthin in the USA than in Spain. Possible methodological differences between these two studies could only explain a part of the important differences found on food sources of vitamin $\mathrm{C}$, vitamin $\mathrm{E}$ and carotenoids in the USA and Spain.

Two studies carried out in northern European countries, Germany (Heseker \& Schneider, 1994) and Finland (Jarvinen, 1995), presented a pattern of food sources of studied nutrients more similar to that found in the USA, whereas a study conducted in Italy showed a pattern more similar to that in Spain (Krogh et al. 1993). A comparison of patterns of food consumption among the ten European countries of the EPIC study showed that the Spanish cohort had greater absolute and relative intakes of leafy and fruiting vegetables and of citrus fruits, and lower of root vegetables than northern European countries (Agudo et al. 2002). These differences would be reflected on the profile of specific carotenoid intake: a probable higher intake of vitamin $C$, lutein, $\beta$-cryptoxanthin and zeaxanthin, and relatively lower intake of $\alpha$-carotene and $\beta$-carotene in Spain in comparison with northern European countries. With regard to main dietary sources of vitamin $\mathrm{E}$, mean intake of vegetable margarine was about $2.5 \mathrm{~g} / \mathrm{d}$ in Spain and almost four times higher in northern Europe, whereas mean vegetable oil consumption was eleven times greater in Spain (approximately 27.0 v. $2.5 \mathrm{~g} / \mathrm{d}$; Linseisen et al. 2002). Other vitamin-fortified processed foods, such as ready-to-eat cereals and juices, were consumed in much lower amounts (1.2 v. 19.0 and 36.0 v. $86.0 \mathrm{~g} / \mathrm{d}$ respectively) in Spain compared with northern Europe (Wirfält et al. 2002). Another study conducted in five European countries (O'Neill et al. 2001), even though limited because of its small sample size, showed that contribution of fresh tomato to lycopene intake was much greater in Spain than in other western countries, while tomato products and pizza were the main sources in other western countries. Sources of lycopene in Canada were similar to those of other non-Mediterranean countries (Johnson-Down et al. 2002).

Overall, sources of antioxidants tended to be from fresh, unprocessed foods rather than processed or fortified foods in Mediterranean countries such as Spain or Italy compared with the USA, Canada and northern European countries. This agrees with the accumulating evidence on redox modulators and disease prevention, which has led to consideration of foods as complex mixtures of bioactive compounds that, in combination, may have benefits beyond those of any single constituent (Byers, 2000; McDermott, 2000; de Lorgeril \& Salen, 2001).

There are two previous studies presenting food sources of nutrients with redox properties in Spain. In a study conducted on a representative sample of the adult population of the Catalan region (Gascón-Vila et al. 1999), a lower contribution of vegetables to vitamin $C$ and $\beta$-carotene intake was observed. These differences could be partly attributed to differences in the population, in the dietary assessment method or, to a lesser extent, to the use of different food composition databases. The other study conducted on a representative sample of Spanish households tried to ascertain Spanish food sources of carotenoids (Granado et al. 1996). Results from that study were quite different from those of the Spanish EPIC cohort with regard to sources of lycopene, lutein and zeaxanthin. Watermelon, which is rich in lycopene, was estimated to provide $50 \%$ of lycopene intake in the study of Granado et al. (1996), while in the present study the value was $3 \%$. Even though it is possible that this $3 \%$ could be an underestimate, individual dietary data from our present cohort and from Spanish dietary surveys (Aranceta et al. 1990, 1994; Serra-Majem et al. 1996; Mataix Verdú et al. 1999; Serra-Majem et al. 2000; Tur-Marí \& Obrador, 2002) 
show that watermelon, which is a seasonal food consumed during the summer, accounts for $<7 \%$ total fruit intake. There are some methodological drawbacks in this previous study that could partly account for their results. The calculations in the study were based on family budget surveys, which have several limitations in the estimation of food consumption (Nelson \& Bingham, 1997). Data on food availability tend to overestimate intake in a non-homogeneous manner, and overestimation is greater for foods with a greater proportion of non-edible parts and greater losses during preparation (Nelson \& Bingham, 1997). Another factor that could partly explain these differences is that, in the present study, all foods consumed were used to calculate their contribution to carotenoid intake, while the analysis of the results of Granado et al. (1996) only included fourteen fruits and fifteen vegetables that they estimated to account for $95 \%$ of fruit and vegetable intake. Finally, differences in estimation could be also due to the fact that Granado et al. (1996) estimated food sources of serum concentration of carotenoids, which is different from sources of intake since serum concentration depends on bioavailability.

The strengths of the present study lie in its large sample size (41 446 subjects) and the instruments used. A validated interviewer-administered diet history method with $>750$ items (foods, beverages and local recipes) was used. This is considered a reliable assessment instrument to estimate usual food intake and to capture seasonal variations in dietary habits (Nelson \& Bingham, 1997). To estimate intake of specific carotenoids, a recently available food composition database was employed: the database was compliled from analyses of indigenous foods by HPLC (Olmedilla et al. 1996). One limitation of the Spanish EPIC study is that it was based on a non-representative sample of the general population. However, the number of subjects was very large, the participation rate was similar to that of Spanish nutritional surveys, and subjects came from different social backgrounds and different geographical areas. In addition, the pattern of dietary intake was very similar to that observed in population-based surveys carried out in the Spanish regions included in the present study (Aranceta et al. 1990; Mataix Verdú et al. 1999).

In conclusion, the results of the present study may allow identification of antioxidant-rich foods typical of a Mediterranean style-diet that may have a role on the protection against chronic diseases. Furthermore, information on the contribution of each food and food group to total intake of redox modulators may be useful to clinicians, public health planners and food-policy makers. In addition, epidemiologists may apply this information to the development or improvement of dietary assessment instruments. Finally, knowledge of the main food sources of the assessed nutrients could provide insight into the interpretation of epidemiological studies investigating the role of diet in health and disease.

\section{Acknowledgements}

This study is part of the EPIC-Spain study. The EPIC study is coordinated by the Unit of Nutrition and Cancer of the International Agency for Research on Cancer (IARC),
Agreement NTR/2000/01. It receives financial support from the European Commission (Agreement SPC.2002332), the Health Research Fund (FIS) of the Spanish Ministry of Health (Exp. 96 0032), and the participating Regional Governments. The EPIC centres from Barcelona, Granada and Murcia received funds from the Net of Centres of Epidemiology and Public Health from the Carlos III Health Institute.

\section{References}

Agudo A, Slimani N, Ocké MC, et al. (2002) Consumption of vegetables, fruit and other plant foods in the European Prospective Investigation into Cancer and Nutrition (EPIC) cohorts from 10 European countries. Public Health Nutr 5, 1179-1196.

Aranceta J, Pérez C, Amela C \& Garcia-Herrera R (1994) Nutritional Survey of the Community of Madrid. Madrid, Spain: Technical documents of Public Health, no. 18. Madrid: General Directorate of Prevention and Health Promotion.

Aranceta J, Pérez C, Eguileor I, Gonzaloz de Goldeano L, Mataix J \& Sáez; de Burauga J (1990) Nutritional Survey. Technical Documents of Public Health Series A, no. 9. Vitoria: Government of the Basq country.

Byers TE (2000) Nutrition and Cancer: Ten lessons from the 20th century. Nutrition 16, 561-563.

de Lorgeril M \& Salen P (2001) Mediterranean type of diet for the prevention of coronary heart disease. Int J Vitam Nutr Res 71, 166-172.

EPIC Group of Spain (1997) Relative validity and reproducibility of a diet history questionnaire in Spain. II. Nutrients. Int J Epidemiol 26, Suppl. 1, S100-S109.

EPIC Group of Spain (1999) Dietary intake of vegetables and fruits among adults in five regions of Spain. Eur J Clin Nutr 53, 174-180.

Fairfield KM \& Fletcher RH (2002) Vitamins for chronic disease prevention in adults. $J$ Am Med Assoc 287, 3116-3126.

Frei B (1994) Natural Antioxidants in Human Health and Disease. San Diego, CA: Academic Press, Inc.

Gascón-Vila P, Ribas L, García-Closas R, Farrán Codina A \& Serra-Majem L (1999) Dietary sources of vitamin A, C, E and $\beta$-carotene in an adult Mediterranean population. Gac Sanit 13, 22-29.

Granado F, Olmedilla B, Blanco I \& Rojas-Hidalgo E (1996) Major fruit and vegetable contributors to the main serum carotenoids in the Spanish diet. Eur J Clin Nutr 50, 246-250.

Halliwell B (2000) The antioxidant paradox. Lancet 355, $1179-1180$

Heseker H \& Schneider R (1994) Requirement and supply of vitamin $\mathrm{C}, \mathrm{E}$, and $\beta$-carotene for elderly men and women. Eur $J$ Clin Nutr 48, 118-127.

Jarvinen R (1995) Carotenoids, retinoids, tocopherols and tocotrienols in the diet; the Finnish Mobile Clinic Health Examination Survey. Int J Vitam Nutr Res 65, 24-30.

Johnson-Down L, Saudny-Unterberger H \& Gray-Donald K (2002) Food habits of Canadians: lutein and lycopene intake in the Canadian population. J Am Diet Assoc 102, 988-991.

Kritharides L \& Stocker R (2002) The use of antioxidant supplements in coronary heart disease. Atherosclerosis 164, 211-219.

Krogh V, Freudenheim JL, D'Amicis A, Scaccini C, Sette S, Ferro-Luzzi A \& Trevisan M (1993) Food sources of nutrients of the diet of elderly Italians: II. Micronutrients. Int $J$ Nutr 22, $869-877$.

Linseisen J, Bergström E, Gafá L, et al. (2002) Consumption of added fats and oils in the European Prospective Investigation into Cancer and Nutrition (EPIC) centres across 10 European 
countries as assessed by 24-hour dietary recalls. Public Health Nutr 5, 1227-1242.

McDermott JH (2000) Antioxidant nutrients: current dietary recommendations and research update. J Am Pharm Assoc 40, $785-799$.

Mataix Verdú J, Llopis González J, Martínez de Victoria E, Montellano Delgado MA, López Frías M \& Aranda Remirez P (1999) Evaluation of the Nutritional Status in the Autonomous Community of Andalucia. Granada: Public Health Service \& Institute of Nutrition and Food Technology of the University of Granada.

Moreno LA, Sarría A \& Popkin BM (2002) The nutrition transition in Spain: a European Mediterranean country. Eur $J$ Clin Nutr 56, 992-1003.

Nelson M \& Bingham SA (1997) Assessment of food consumption and nutrient intake. In Design Concepts in Nutritional Epidemiology, [BM Margetts and M Nelson, editors]. Oxford: Oxford University Press.

Olmedilla B, Granado F, Blanco I, Gil-Martínez E \& Rojas Hidalgo E (1996) Contenido de Carotenoides en Frutas y Verduras de Mayor Consumo en España (Carotenoid Content of Fruits and Vegetables Most Frequently Consumed in Spain). Madrid: Instituto Nacional de la Salud (INSALUD), Secretaría General.

O'Neill ME, Carroll Y, Corridan B, Olmedilla B, Granado F, Blanco I, Van den Berg H, Hiniger I, Rousell A-M, Chopra M, et al. (2001) A European carotenoid database to assess carotenoid intakes and its use in a five-country comparative study. Br J Nutr 85, 499-507.

Parkin DM, Whelan SL, Ferlay J, Raymond L \& Young J (editors) (1997) Cancer Incidence in Five Continents, vol. VII. IARC Sci. Publ. no. 143. Lyon: International Agency for Research on Cancer.

Pera G, González CA \& EPIC Group of Spain (1999) Consumo de suplementos vitamínicos en población adulta sana de cinco provincias de España (Intake of vitamin supplements in adult healthy population in five Spanish provinces). Gac Sanit 13, 326-327.

Serra-Majem L, Ribas L, García-Closas R, et al. (1996) Evaluation of the nutricional status of the catalan population (1992-93). Barcelona: Department of Health and Social Security Generalitat de Catalunya.

Serra-Majem L, Ribas Barba L \& Arman Navarro A on behalf of the research grioup of the ENCA (2000) Nutritional Survey in Canary Islands 1997-98,Tenerife: Canary Service of Health.

Slimani N, Farran A, Torrent M, Farriol N, Moreuo I, Hémon B, Gonźalez CA \& Riboli E (1996) European Prospective Investigation into Cancer and Nutrition (EPIC): Food Composition Tables - Spain, 2nd ed. Lyon: International Agency for Research on Cancer.

Subar AF, Krebs-Smith SM, Cook A \& Kahle LL (1998) Dietary sources of nutrients among US adults, 1989 to 1991. J Am Diet Assoc 98, 537-547.

Trichopoulou A \& Vasilopoulou E (2000) Mediterranean diet and longevity. Br J Nutr 84, Suppl. 2, S205-S209.

Tundstall-Pedoe H, Kuulasmaa K, Mahonen M, Tolonen H, Ruokokoski E \& Amouyel P (1999) Contribution of trends in survival and coronary-event rates to changes in coronary heart disease mortality: 10-year results from 37 WHO MONICA project populations. Monitoring trends and determinants in cardiovascular disease. Lancet 353, 1547-1557.

Tur-Marí JA \& Obrador A (2002) Nutritional Study of the Baleares Islands. ENIB (1999-2000). Palma de Mallorca: Institute of Baleares Studies.

United Nations International Children's Emergency Fund (2003)
The state of the world's children 2003. http://www.unicef org/spanish/sowc03/tables/table7.html

Vandenlangenberg GM, Brady WE, Nebeling LC, et al. (1996) Influence of using different source of carotenoid data in epidemiologic studies. J Am Diet Assoc 96, 1271-1275.

Wirfält E, McTaggart A, Pala V, Block G, Forman M, Bouveu PE, Stacewicz-Sapuntzareis M \& Mares-Perlman JA (2002) Food sources of carbohydrates in a European cohort of adults. Public Health Nutr 5, 1197-1215.

World Cancer Research Fund (1997) Food, Nutrition and the Prevention of Cancer. A Global Perspective. Washington, DC: American Institute for Cancer Research.

World Health Organization (2003) Regional Office for Europe. Health for all database. www.who.dk (accessed 15 April 2003).

\section{Appendix}

\section{Classification of foods}

Green leafy vegetables: parsley, seaweeds, chard, lucerne, borage, leek, thistle, spinach, chicory, turnip (top), lettuce, endive (Cichorium intybus), endive (Cichorium endivia).

Cruciferous vegetables: cabbage, red cabbage, Brussel sprouts, cauliflower.

Root vegetables: turnip, radish, beetroot, carrot, Yecla's carrot (Daucus carota), charlotte carrot, parsnip, celery.

Fruiting vegetables: green beans, tomato, artichoke, aubergine, courgette, gherkins, pumpkin, capers, large capers, cucumber, sweet pepper, green chili, avocado.

Grain and pod vegetables: maize, peas.

Stalk vegetables: bamboo, palm hearts, leek, asparagus, sprouted soyabean, celeriac, caper stems.

Potatoes: potatoes, chips.

Citrus fruits: lemon, mandarin, orange, grapefruit.

Non-citrus fruits: apricot, cherry, custard apple, plum, strawberry, pomegranate, fig, kiwi, mango, apple, melon, nectarine, medlar, date plum, pear, pineapple, banana, watermelon, grape, peach, dried peaches, prickly pear, peach with syrup, canned pineapple, dried plum, dried fig, raisins, dates.

Juices: orange juice, lemon juice, grape juice, tomato juice, non-specified fruit juice.

Pulses (legumes): chickpeas, lentils, white beans, black beans, fava beans.

Grains: bread, ready-to-eat cereals, rice, pasta, flour, wheatgerm.

Onion and garlic: garlic, young garlic, pickled onions, onion.

Condiments and sauces: tomato sauce, ketchup, Spanish sauce (tomato-based sauce), mayonnaise, bechamel sauce, fried tomato and onion sauce.

Nuts and seeds: lupin, chestnut, coconut, almond, hazelnut, peanut, walnut, seeds (sunflower or pumpkin), pistachio, pine kernels.

Milk and dairy products: milk, yoghurt, cheese, milkbased desserts.

Fish and shellfish: white fish, blue fish, shellfish, molluscs.

Meat and poultry: beef, veal, lamb, pork, sheep, pig, game, offal, processed meat (ham, bacon, sausage, cold cuts), chicken, turkey, duck, foie gras.

Added fats: oils (olive, sunflower, maize, soyabean), butter, margarine, lard. 